\title{
A DECLARAÇÃO UNIVERSAL DOS DIREITOS HUMANOS E AS RELAÇÕES DE GÊNERO: APORTES PARA A EDUCAÇÃO
}

\author{
Geraldo Augusto Locks ${ }^{1}$ \\ Mareli Eliane Graupe ${ }^{2}$ \\ Josilaine Pereira Antunes ${ }^{3}$
}

Resumo: Neste texto analisamos a inserção ou ausência da categoria gênero nas Declarações dos Direitos Humanos de 1948 e 1998. Esses documentos são uma base para os tratados internacionais e uma referência importante para a elaboração das políticas públicas. A pesquisa aponta lacunas e indica novas reflexões para que a Declaração seja assumida, contemplando as relações de gênero e servindo como um aporte ético para a-humanidade, e especialmente para a inclusão de gênero $e$ direitos humanos no campo educacional.

Palavras-chave: Declaração Universal dos Direitos Humanos. Relações de gênero. Educação.

Resumen: En este trabajo se analiza la inclusión o no de la categoría de género en las Declaraciones de Derechos Humanos de 1948 y 1998. Estos documentos son la base de los tratados internacionales y una referencia importante para la elaboración de políticas públicas. La investigación muestra lagunas e indica un nuevo pensamiento de la Declaración que deberá adopta, teniendo en cuenta las relaciones de género y que actúa como una contribución ética de la humanidad y en especial para la inclusión de género y los derechos humanos en el campo de la educación.

Palabras claves: Declaración Universal de los Derechos Humanos. Las relaciones de género. Educación.

\section{Introdução}

A Declaração Universal dos Direitos Humanos de 1948 (DUDH) tem servido de plataforma para a consignação dos direitos humanos desde a última

\footnotetext{
${ }^{1}$ Doutor em Antropologia Social. Professor no Programa de Pós-Graduação em Educação, na Universidade do Planalto Catarinense, Brasil. E-mail: geraldolocks@gmail.com.

2 Doutora em Educação. Professora no Programa de Pós-Graduação em Educação, na Universidade do Planalto Catarinense, Brasil. E-mail: mareligraupe@hotmail.com.

${ }_{3}$ Mestra em Educação. Professora na Universidade do Planalto Catarinense e professora de Educação Infantil. E-mail: antunesjo@hotmail.com.
}

LOCKS, Geraldo Augusto; GRAUPE, Mareli Eliane; ANTUNES, Josilaine Pereira. A Declaração Universal dos Direitos Humanos e as relações de gênero: aportes para a educação. Revista Sul-Americana de Filosofia e Educação. Número 26: maio-out./2016, p. 81-103. 
metade do século XX. Dois anos e meio após a criação da Organização das Nações Unidas, sua Assembleia Geral a proclamou como "o ideal comum a ser atingido por todos os povos e todas as nações".

Ela emergiu no contexto extremamente singular: o mundo cansado de guerra, ainda que todo o século XX, como indicou Eric Hobsbawn em seu livro Era dos Extremos (1988), tenha sido um século de guerra. As atrocidades, a barbárie, o horror, o genocídio humano e toda forma de desrespeito da dignidade humana até então nunca foram registrados na história da espécie humana.

Portanto, a Declaração tem no seu nascedouro uma disposição das nações beligerantes um desejo de paz no futuro, negociar os conflitos pela via diplomática, enfim, fortalecer a democracia e o respeito aos Direitos Humanos. Contudo, Alencar (1998), adverte para o fato de que, contraditoriamente, ela é engendrada num ambiente mundial de "paz armada". Nasce quando o mundo está mergulhado em outra guerra, chamada "guerra fria", marcada pela bipolaridade das duas superpotências, EUA e URSS. Como é sabido, as duas potências tiveram como base batalhas nucleares globais que a qualquer momento uma ou outra potência detinha o poder de destruição da humanidade. Esta tensão somente conheceu sua trégua com a queda do Muro de Berlin em 1989. Trata-se de uma Declaração histórica, realizada num clima tenso, denso, sectário, como afirma Alencar (idem, p. 27). De qualquer maneira naquele momento histórico, o documento foi expressão inegavelmente de objetivos comuns e valores compartilhados entre seus signatários e nisto reside sua legitimidade.

Convém destacar aqui o caráter educativo da DUDH. Em seu preâmbulo, no último parágrafo, pode ser identificado um apelo, para que

cada indivíduo e cada órgão da sociedade se esforcem, através do ensino e da educação, por promover o respeito a esses direitos e liberdades e pela adoção de medidas progressivas de caráter nacional e internacional, por assegurar o seu reconhecimento $e$ a sua observância universais e efetivos, tanto entre os povos dos próprios Estados membros quanto entre os povos dos territórios sob sua jurisdição (ALENCAR, 1998, p. 10). 
A Declaração tem status de lei branca (soft law). Leis brancas são consideradas moralmente, mas não juridicamente obrigatórias para os Governos de Estados, que aceitam subscrevê-las e adotá-las, e muitas vezes servem de base para o desenvolvimento de uma lei stritu senso (hard law). Outro exemplo de lei banca é a Carta da Terra ${ }^{4}$, uma declaração de princípios éticos fundamentais para a construção no século XXI, de uma sociedade global justa, sustentável e pacífica. A Declaração Universal dos Direitos Humanos, mesmo na condição de lei branca continua válida, sendo base para outros tratados internacionais, referência indispensável no Poder Judiciário e a Organização das Nações Unidas a tem como ideal comum a ser alcançado pela humanidade.

Bobbio (1992) defende a tese de que a DUDH serviu como uma orientação para o desenvolvimento da sociedade, contribuindo para que os seres humanos fossem livres e iguais. Neste contexto, Zenaide ${ }^{5}$ corrobora ao afirmar que a DUDH "se apresenta como um marco ético-político de construção de uma cultura universal de respeito aos direitos humanos [...]" (2008, p. 130).

A DUDH embora seja considerada como universal, como afirma Alencar (1998, p. 28) "universal no nome e em diversos princípios, a Declaração é histórica, temporal, datada. E, por isso, nesta virada de século, já insuficiente em vários aspectos". Ainda convém ressaltar que a nossa leitura é feita com as lentes da atualidade, datada e de uma perspectiva epistemológica específica.

Neste contexto é importante lembrar que há outros documentos históricos que tratam sobre os Direitos Humanos, como por exemplo, a Declaração dos

\footnotetext{
${ }^{4}$ Disponível em: http://www.cartadaterrabrasil.org/prt/text.html; Acesso: 16 de julho de 2015.

5 Por ocasião dos sessenta anos da Declaração Universal dos Direitos Humanos, o Ministério da Educação, por meio da Secretaria de Educação Continuada, Alfabetização e Diversidade promoveu ações voltadas para a Educação em Direitos Humanos. Foi realizado o Projeto Capacitação de Educadores da Rede Básica em Educação em Direitos Humanos, coordenado pela Universidade Federal da Paraíba em regime de colaboração com 16 universidades federais, com o objetivo de promover a cultura dos Direitos Humanos, o diálogo e o respeito à diversidade. O resultado deste trabalho está comtemplado em dois volumes disponíveis online em:

http://www.dhnet.org.br/dados/livros/edh/a_pdf/livro_dirhumanos_volume1.pdf http://www.dhnet.org.br/dados/livros/edh/a_pdf/livro_dirhumanos_volume2.pdf Data de acesso: 08 de abril de 2016.
} 
Direitos do Homem e do Cidadão de 26 de agosto de $1789^{6}$, fruto da Revolução Francesa. A Revolução Francesa inspirou os ideais representativos dos direitos humanos na tríade: a liberdade, igualdade e fraternidade, ainda que numa perspectiva liberal.

O autor alemão Karl Marx, em sua obra "A questão Judaica" (1993), escrita em 1843, fez uma crítica contundente à Declaração dos Direitos do Homem e do Cidadão, apontando para a necessidade de se distinguir entre "os direitos do homem e os direitos do cidadão". Problematizava a perspectiva dos "direitos do homem", que segundo o autor, configura direitos individualizados e egoístas,ou seja, direitos de um membro da sociedade, do homem separado dos outros homens e da sociedade. Enquanto que, a percepção dos "direitos do cidadão" apontava para os direitos do sujeito "em-relação-com" outros homens, com a comunidade, a sociedade. Isto é, direitos compartilhados ou solidários dir-se-ia contemporaneamente.

No ano de 1791, Olympe de Gouges ${ }^{7}$ escreveu a Declaração dos Direitos da Mulher e da Cidadã em resposta à Declaração dos Direitos do Homem e do Cidadão. Nesse documento ela fomenta o desejo de igualdade entre homens $e$ mulheres, desafia a conduta injusta da autoridade masculina e reivindica a igualdade de direitos da mulher à educação, à política, ao voto. Após 157 anos da execução de Olympe de Gouges foi publicada a Declaração Universal dos Direitos Humanos. Nesse período já existiam documentos históricos que buscavam tratar diretamente dos direitos das mulheres, e também, exemplos de mulheres que lutaram no fomento de políticas públicas visando à redução das desigualdades

\footnotetext{
${ }^{6}$ Declaração de direitos do homem e do cidadão - 1789 (em português). Universidade de São Paulo. Biblioteca Virtual de Direitos Humanos (1978). Disponível em: http://www.direitoshumanos.usp.br/index.php/Documentos-anteriores-\%C3\%A0cria\%C3\%A7\%C3\%A3o-da-Sociedade-das-Na\%C3\%A7\%C3\%B5es-at\%C3\%A9-1919/declaracaode-direitos-do-homem-e-do-cidadao-1789.html; Acesso: 14 de janeiro de 2015.

${ }_{7}$ Pseudônimo de Marie Gouze. Olympe de Gouges foi uma feminista, defensora da democracia, dos direitos iguais para homens e mulheres. Nasceu dia 07 de maio de 1748 e foi guilhotinada no dia 03 de novembro de 1793. Informações disponíveis: http://www.historia.uff.br/nec/olympe-degouges-mulheres-e-revolucao Acesso: 08 de abril de 2016.
} 
entre homens e mulheres, assim como a violação dos seus direitos enquanto cidadãs.

\section{As questões de gênero}

Neste texto queremos refletir acerca de uma das lacunas da DUDH a inserção da categoria gênero e suas implicações na construção de relações mais justas e democráticas entre mulheres e homens. O texto manteve a tradicional generalização de homem, termo para representar homens e mulheres. Observa-se o caldo cultural predominante na gênese da escrita, no qual o masculino é a expressão e símbolo maior de poder da espécie humana.

O termo "mulheres" ${ }^{8}$ aparece somente duas vezes na DUDH. Primeiramente, ele surge num contexto geral, em que designa a igualdade de direitos dos homens e das mulheres no que se refere à promoção de progresso social, melhores condições de vida e liberdade. No artigo XVI, a palavra "mulheres" emerge num contexto em que afirma que homens e mulheres maiores de idade sem distinção de raça, nação e religião podem se casar e formar uma família. Também, que possuem direitos iguais em relação à duração e ao término do casamento.

Os direitos das mulheres aparecem de forma generalizada e na prática, esses direitos nem sempre são cumpridos em função da influência da cultura, da tradição e dos preconceitos que foram sendo combinados para excluir a maioria das mulheres dos direitos humanos, delegando, muitas delas, para uma posição

\footnotetext{
8 Considerando que os povos das Nações Unidas reafirmaram, na Carta, sua fé nos direitos humanos fundamentais, na dignidade e no valor da pessoa humana e na igualdade de direitos dos homens e das mulheres, e que decidiram promover o progresso social e melhores condições de vida em uma liberdade mais ampla. (Preâmbulo)

Artigo XVI, 1. Os homens e mulheres de maior idade, sem qualquer restrição de raça, nacionalidade ou religião, têm o direito de contrair matrimônio e fundar uma família. Gozam de iguais direitos em relação ao casamento, sua duração e sua dissolução.

Disponível em: http://portal.mi.gov.br/sedh/ct/legis intern/ddh bib inter universal.htm, Acesso: 14 de janeiro de 2015.

9 Sobre a diferença conceitual entre as categorias "mulher" $e$ "mulheres" sugerimos o artigo "Relações de gênero como categoria transversal na historiografia contemporânea", de Joana Maria Pedro.
} 
secundária na família e na sociedade. Essa marginalização das mulheres em relação ao acesso aos direitos humanos persiste a um nível de disparidade no cotidiano, na realidade de umas e outras mulheres, pois a forma como a cultura, a tradição, os valores determinam sobre o que é adequado para as mulheres e os homens não se altera quando uma declaração, resolução ou lei entra em vigor, mesmo que essas sejam amplamente divulgadas e acompanhadas de campanhas de sensibilização e de formação.

Notável também é o fato de que quando a DUDH em seu Art. 2 anuncia "Todo homem tem capacidade para gozar os direitos e as liberdades estabelecidas nesta declaração sem distinção de qualquer espécie, seja de raça, cor, sexo, língua, religião, opinião política ou de outra natureza, origem nacional ou social, riqueza, nascimento ou qualquer outra condição", o Artigo relaciona sexo e não relaciona a categoria gênero. Claro, gênero é uma categoria com todas as implicações epistemológicas e políticas, trazida à cena pelo movimento feminista mundial após a década de 1950.

Neste sentido a DUDH, examinada depois de sessenta e seis anos, observamos que opera um verdadeiro apartheid em relação aos direitos das mulheres no que diz respeito à sua singularidade, especificidade, complexidade histórica, particularmente, a condição de subalternidade em relação ao homem. Hoje, pode-se compreender que a Declaração dos Direitos Humanos é uma declaração fundada no e para o padrão normativo heterossexual que se diz hegemônico na sociedade. Ela não responde ao direito de outras orientações sexuais ou as diferentes expressões da sexualidade, daí que o apartheid não se coloca somente em relação às mulheres, mas a todas as outras expressões da sexualidade que não seja a heterossexualidade.

Gênero é uma categoria que se inscreve entre aquelas palavras "como as ideias e as coisas que elas são feitas para significar, têm uma história", como afirma Scott na abertura de seu texto, Gênero: uma categoria útil de análise histórica. Scott referindo-se à "litania, gênero, raça e classe", diz que 
as pesquisadoras feministas que tinham uma visão política mais global apelavam regularmente a estas três categorias para a escrita de uma nova história. $\mathrm{O}$ interesse pelas categorias de classe, de raça e de gênero, assinalava, primeiramente, o engajamento do pesquisador numa história que incluía os cursos das (os) oprimidas (os) e numa análise do sentido e da natureza de sua opressão; (...) assinalava que as desigualdades de poder são organizadas segundo estes três eixos, pelo menos (SCOTT, 1995, p. 73).

As historiadoras feministas têm utilizado uma diversidade de perspectivas na análise do gênero que podem ser resumidas em três grandes abordagens teóricas:

A primeira tentativa inteiramente feminista empenha-se em explicar as origens do patriarcado. A segunda se situa no interior de uma tradição marxista e busca um compromisso com as críticas feministas. A terceira fundamentalmente, dividida entre o pós-estruturalismo francês e as teorias angloamericanas de relação do objeto (object-relation theories), se inspira nessas diferentes escolas de psicanálise para explicar a produção e reprodução da identidade de gênero do sujeito (SCOTT, 1995, p. 77).

A abordagem de gênero como uma categoria analítica somente surgiu no final do século XX. Ela está ausente das principais perspectivas de teoria social formuladas do século XVIII até meados do século XX. Gênero, como uma possibilidade de falar de sistemas de relações sociais ou sexuais, não tinha surgido. Seu uso emergiu num momento de grande efervescência teórica. O termo faz parte da tentativa das feministas contemporâneas da classe média e alta, "para reivindicar um certo terreno de definição, para sublinhar a incapacidade das teorias existentes para explicar as persistentes desigualdades entre as mulheres e os homens", (SCOTT, 1995, p. 85).

Gênero tem sido usado, desde a década de 70, para teorizar a questão da diferença sexual e, utilizado inicialmente pelas feministas americanas, trouxe inúmeras contribuições. A ênfase é dada fundamentalmente no caráter social das distinções baseadas nos sexos, buscando desvelar o fantasma da "naturalização", presente nas explicações que justificam as desigualdades entre os seres masculinos e femininos. 
Com a incorporação do gênero como categoria analítica, tem-se procurado demonstrar que os comportamentos ou valores que são aceitos em uma sociedade, num determinado momento histórico, podem ser rejeitados em outros períodos. Assim, destacar as diferenças a partir do reconhecimento de que a realidade histórica é social e culturalmente constituída tornou-se um pressuposto para entender essa categoria, permitindo perceber a existência de processos históricos diferentes e simultâneos, bem como abrir um leque de possibilidades de focos de análise.

Segundo Pitanguy e Miranda (2006), a DUDH foi formulada em um momento histórico em que as mulheres ocupavam ainda posições secundárias na vida econômica, política e familiar. Esse documento está fundamentado em um conceito de humanidade constituído a partir da figura do homem, portanto falta à DUDH uma perspectiva de gênero.

No ano de 1998 em função do 50 a aniversário da DUDH foi elaborado pelo Comitê Latino-Americano e do Caribe para a Defesa dos Direitos da Mulher $\left(\mathrm{CLADEM}^{10}\right)$, juntamente com outras organizações regionais e internacionais, uma proposta intitulada "Declaração dos Direitos Humanos desde uma perspectiva de gênero" 11 (DUDHG) que deveria ser adotada pelos Estados membros das Nações Unidas.

O Comitê via a ocasião oportuna para que os Estados renovassem seu compromisso com os direitos humanos, incorporando as perspectivas de gênero $e$ etnia. Assim como a DUDH de 1948 constituiu um código ético para a segunda metade do século XX, considerava-se necessário que no limiar do novo milênio, os Estados aprovassem outro documento de proteção internacional dos direitos

\footnotetext{
${ }^{10} \mathrm{O}$ CLADEM é uma rede feminista que trabalha para contribuir à plena vigência dos direitos das mulheres na América Latina e Caribe, utilizando o direito como um instrumento de mudança. Conta com status consultivo na Categoria II perante as Nações Unidas desde 1995 e goza de reconhecimento para participar nas atividades da OEA desde 2002. Disponível em http://www.cladem.org/index.php?option=com_content\&view=article\&id=488\&Itemid=246. Acesso em: 03.08.2015.

${ }^{11}$ Contribuições ao $50^{\circ}$ Aniversário da Declaração Universal dos Direitos Humanos. Documento N. ${ }^{\circ}$ E/CN.4/1998/NGO/3. http://www.dhnet.org.br/direitos/deconu/textos/cladem.htm, Acesso em: 13 de janeiro de 2015.
} 
humanos, que integrasse os avanços realizados na teoria e na prática dos direitos humanos desde 1948, sem invalidar, de forma alguma, as conquistas da DUDH.

O objetivo desta reflexão, a seguir, é percorrer a o texto da "Declaração Universal dos Direitos Humanos desde uma perspectiva de gênero" (DUDHG) atento a aplicação do conceito de gênero e suas relações com os direitos humanos. E ao mesmo, tempo vamos estabelecendo um diálogo com as autoras feministas, como por exemplo, Joan Scott e outras.

\section{O preâmbulo}

A primeira peça do documento, ao considerar a gênese da DUDH, denuncia o conceito de gênero limitado e restrito a um padrão de homem quando diz:

que a formulação contemporânea dos direitos humanos emergiu em um contexto histórico no qual o conceito de ser humano encontrava-se, em grande medida, limitado ao do macho, ocidental, branco, adulto, heterossexual e dono de um patrimônio (DUDHG, p. 1).

As mulheres, melhor ainda, as feministas se encontravam preocupadas com esta concepção limitada e unilateral de gênero, por não considerar a história das mulheres e seus aspectos relacionais com os homens, sendo as mulheres compreendias separadamente, como já denunciavam os primeiros estudos femininos da década de 1970 (SCOTT, 1995); gênero entendido assim, "manteria restringido os direitos das mulheres, indígenas, homossexuais e lésbicas, meninos, meninas, idosos, pessoas portadoras de deficiência e de outros grupos" (DUDHG, p. 1). De outro lado, achavam-se convencidas de que "um conceito holístico e inclusivo de humanidade seria necessário para a plena realização dos direitos humanos; passavam então a reafirmar a indivisibilidade, universalidade $e$ interdependência dos direitos humanos" (DUDHG, p. 1). 
Na primeira parte, o artigo 1 já apresenta a concepção de gênero relacional, ampliada e referida aos direitos, ao reivindicar o "direito de identidade $e$ cidadania" 12 para todas as pessoas, enunciando que:

Todas as mulheres $e$ homens nascem livres $e$ iguais em dignidade e direitos. Todos os seres humanos têm direito a desfrutar todos os direitos humanos, sem distinção alguma baseada em raça, etnia, idade, sexo, orientação sexual, deficiência física ou mental, idioma, religião (...) (id, p. 1).

$\mathrm{O}$ artigo 2 insiste no direito à identidade individual e coletiva, avançando inclusive para a defesa de qualquer condição de conjugalidade, afirmando que:

todas as pessoas têm direito a sua própria identidade como indivíduos, como membros de grupos com os quais se identificam, como membros de uma nação e como cidadãos (ãs) do mundo, com o grau de autonomia $e$ autodeterminação, em todas as esferas, necessário para preservar sua dignidade e seu sentido de auto-valia. Este direito à identidade não será afetado negativamente pelo matrimônio (id. p. 1).

A DUDHG destaca a relação de gênero também no mundo da exploração do trabalho, sobretudo, aquele que coloca a mulher em condições análogas ao trabalho escravo, ao tráfico de mulheres e crianças: "a escravidão, a servidão e o tráfico de mulheres, meninas e meninos, em todas as suas formas, incluindo aquelas que possam ocorrer em relações familiares, estão proibidos" (id. art. 2, n. 2, p. 1).

Referindo-se aos bens políticos e materiais em todas as esferas da sociedade e a cargos públicos, aplica a concepção de gênero dizendo que: "todos os seres humanos têm o direito a uma participação igualitária e equitativa em organizações laborais, políticas e sociais, assim como ao acesso a cargos públicos eletivos e não eletivos" (id. art. 3, n. 1, p. 2).

\footnotetext{
12 O conceito de cidadania de acordo com MANCE (2004) articula-se em três dimensões solidárias onde as pessoas tenham condições de a) usufruir e compartilhar bens materiais (alimentação, habitação, saúde, trabalho, transporte, educação, etc); b) usufruir e compartilhar bens simbólicos (auto-estima, afirmação social, reconhecimento de identidade, expressão de sexualidade, dignidade, etc); usufruir e compartilhar bens políticos (participar, opinar, representar, organizar-se, conquistar autonomia, etc.)
} 
A concepção de gênero na DUDHG inclui aquela dimensão reafirmada por Scott ao insistir na liberação do conceito de gênero da esfera doméstica e do parentesco. É claro que aí se constroem e se vivem relações de gênero, "mas não exclusivamente; ele é construído igualmente na economia e na organização política, que pelo menos em nossa sociedade, operam atualmente de maneira amplamente independente do parentesco" (1995, p. 87). Assim determinando que:

Todos os Estados deverão eliminar obstáculos para o pleno $e$ igualitário desfrute dos direitos cívicos por parte das mulheres. Em particular, as mulheres poderão adquirir a cidadania sem discriminação e exercer os mesmo direitos que os homens de participar em todas as esferas da vida pública e política da nação (DDHG, art. 3 , n. 2).

Definitivamente o conceito de "gênero" invade o espaço do Estado em dimensões planetárias uma vez que a ONU é constituída por quase duzentas nações membros. Ele tem que remover obstáculos a tudo o que venha discriminar os direitos de cidadania de mulheres e homens. A DUDHG expõe a urgente resposta aos desafios postos por Scott no final de seu trabalho, como por exemplo: "qual é a relação entre as leis sobre as mulheres e o poder de Estado? Por que (e desde quando) as mulheres são invisíveis como sujeitos históricos ainda que nós saibamos que elas participaram de grandes e pequenos eventos da história humana?" (SCOTT, 1995, p. 93).

A parte II da DUDHG levanta-se a bandeira da paz, ou seja, contempla-se a noção de gênero relacionada ao direito à paz e a uma vida livre de violência. Ora, as estatísticas da própria ONU são pródigas em provar que a mulher é a maior vítima da violência no mundo inteiro. Violência simbólica, física, psicológica, religiosa, política, moral, etc. $\mathrm{O}$ art. 7 é objetivo:

Todas as pessoas têm o direito a uma vida livre de violência e a desfrutar da paz, tanto na esfera pública como na privada. Ninguém será submetido a torturas nem a penas ou tratamentos cruéis, desumanos ou degradantes. Todas as formas de violência contra as mulheres constituem uma violação a seus direitos humanos. A violência não poderá ser usada para negar às pessoas seu direito à moradia, em 
particular a partir de evicções forçadas (DUDHG, art. 7, p. 2).

$\mathrm{O}$ art. 8 insere a noção de gênero nas seguintes outras situações de violência, com ênfase para as crianças e adolescentes:

Pessoas migrantes, deslocadas ou refugiadas e as pessoas em situação de desvantagem por razão de gênero, raça, etnia, idade, convicção ou qualquer outra condição têm direito a medidas especiais de proteção frente à violência (id. art. 8, n. 1 ). Todos os seres humanos têm direito a uma vida livre de conflitos armados (id. art. 8, n. 2). Os ultrajes perpetrados contra mulheres, meninos e meninas em situações de conflito armado, incluindo os assassinatos, as violações, a escravidão sexual $e$ as gravidezes forçadas, constituem crimes contra a humanidade (id. art. 8, n. 3).

Há uma preocupação na DUDHG em sustentar uma relação de gênero igualitária no que concerne ao campo da segurança nacional, tradicionalmente uma questão de domínio civil e militar empreendida pelos homens.

As mulheres e os representantes de grupos em situação de desvantagem têm o direito a participar no processo de tomada de decisões no campo da segurança nacional e na resolução de conflitos (id. art. 9. n. 2, p. 2).

A parte III refere-se aos Direitos Sexuais e Reprodutivos. A DUDHG recolhe um conjunto de direitos exaustivamente discutidos por diferentes segmentos da sociedade civil e política dos últimos cinquenta anos do século $\mathrm{XX}$. A grande maioria deles tem sido sustentada pelas feministas europeias e norte-americanas. Evidentemente que no terceiro mundo, particularmente, no Brasil, esses direitos têm estado na pauta política. É um artigo que rompe com antigos tabus e modelos padronizados defendidos especialmente pela moral religiosa católica extremamente disseminada pelo continente afro-índio-latino. Assim diz o art. 10:

Todos os seres humanos têm direito à autonomia $e$ à autodeterminação no exercício da sexualidade, que inclui o direito aos prazer físico, sexual e emocional, o direito à liberdade na orientação sexual, o direito à informação $e$ educação sobre a sexualidade $e$ o direito à atenção da saúde sexual e reprodutiva para a manutenção do bem-estar físico, mental e social (id. art. 10. p. 2). 
$\mathrm{O}$ artigo 11 , desdobrado em dois pontos, especifica o direito de decidir a vida reprodutiva, do controle da fertilidade, do cuidado da saúde e reprodutiva; outorgando às mulheres o direito inclusive de acesso ao aborto seguro e legal. Aqui a DUDHG mergulha em questóes polêmicas que envolvem costumes, tradições religiosas, códigos éticos, o direito civil e penal de diferentes pontos de vista, sobretudo, no que se refere ao aborto. Contudo o documento ousa com a categoria gênero, reafirmando o protagonismo da mulher:

Mulheres e homens têm o direito de decidir sobre sua vida reprodutiva de maneira livre e de exercer o controle voluntário e seguro de sua fertilidade, livres de discriminação, coerção e/ou violência, assim como o direito de desfrutar dos níveis mais altos de saúde sexual $e$ reprodutiva.

As mulheres têm direito à autonomia na decisão reprodutiva, a qual inclui o acesso ao aborto seguro e legal (id. art. 11, n. 1 e 2).

Na IV parte da DUDHG que diz respeito ao Direito ao Desenvolvimento, o artigo 13 tem seu foco na família em diferentes identidades, enfatizando a paternidade e maternidade na perspectiva do gênero. Portanto quebra o paradigma do modelo de família com "o chefe da família", ao reivindicar direitos e responsabilidades para mulheres e homens:

Toda mulher e homem têm o direito $e$ a responsabilidade de criar e educar seus filhos e filhas, de realizar o trabalho do lar $e$ prover as necessidades da família, inclusive depois da separação ou divórcio (id. art. 13, p. 3).

O trabalho é a chave da questão social. Com o desenvolvimento do modo de produção capitalista industrial (desde 1750), a mulher foi secundarizada e explorada no mundo do trabalho urbano. Excesso de horas trabalhadas e a discriminação na remuneração são indicadores clássicos da exploração do trabalho 
feminino, entre outros. ${ }^{13}$ A realidade da exploração econômica do trabalho feminino persiste especialmente nos países pobres. A DUDHG enfrenta esta questão com determinação:

Todas as pessoas têm direito ao trabalho lucrativo; à livre escolha de seu trabalho; à proteção contra o desemprego; a condições de trabalho seguras, equitativa e satisfatórias e a um nível de vida adequado. Todas as pessoas têm direito a gozar das mesmas oportunidades e tratamento com relação: ao acesso a serviços de orientação profissional e emprego; à segurança no emprego; à igual remuneração por um trabalho de igual valor; à segurança social $e$ a outros benefícios sociais, incluindo o descanso e a recreação (id. art. 14, n. 1 e 2, p. 3).

Finalmente, a $\mathrm{V}$ e última parte da DUDHG evoca os Direitos Ambientais, explicitando a responsabilidade transgeracional, a igualdade de gênero, a solidariedade, a paz, o respeito pelos direitos humanos e a cooperação entre os Estados como bases para a realização do desenvolvimento sustentável e a conservação do meio ambiente. $\mathrm{O}$ art. 16 expressa o direito ao acesso igualitário para homens e mulheres a um ambiente sustentável $e$ às condições de conservação da vida, quando assegura:

Todas as mulheres e homens têm o direito a um ambiente sustentável e a um nível de desenvolvimento adequados para seu bem-estar e dignidade. Todas as mulheres $e$ homens têm o direito ao acesso a tecnologias sensíveis à diversidade biológica, à manutenção dos processos ecológicos essenciais e aos sistemas de conservação da vida na indústria, agricultura, pesca e pastoreio (id. art. 16, n. 1 e 2, p. 3).

Neste tópico dois aspectos são de extrema relevância e tem conquistado avanços significativos nos últimos anos: a preocupação do desenvolvimento com sustentabilidade, sendo uma das suas condições a consciência ambiental. O outro

\footnotetext{
13 "Daens, um grito de justiça" é um filme extraordinário na sua força de imagens e fidelidade histórica às condições de trabalho do mundo industrial europeu do século XIX, colocando a mulher como na condição de explorada e de protagonista na luta pelos direitos. Diretor Stijn Coninx, ano de 1992.
} 
aspecto reside nas tecnologias sociais ${ }^{14}$ econômica, ambiental e culturalmente inclusivas, ferramentas indispensáveis para o bem estar humano combinado com seu meio ambiente.

\section{Políticas públicas no campo dos direitos humanos}

O objetivo deste artigo é de analisar a Declaração Universal dos Direitos Humanos (1948) e a Declaração Universal dos Direitos Humanos desde uma perspectiva de gênero (1998), mas não podemos deixar de mencionar que esses documentos impulsionam e/ou impulsionaram outras políticas públicas de direitos humanos no âmbito global e nacional como, por exemplo, o Programa Mundial de Educação em Direitos Humanos (PMEDH 2005/2014), a Declaração das Nações Unidas sobre a Educação e Formação em Direitos Humanos (Resolução A/66/137/2011), o Plano Nacional de Educação em Direitos Humanos (PNEDH/2007), Programa Nacional de Direitos Humanos (PNDH-3/Decreto $\mathrm{n}^{\circ}$ 7.037/2009) e Diretrizes Nacionais para a Educação em Direitos Humanos (Resolução CNE/CP n. ${ }^{\circ} 1 / 2012$ ).

No Programa Mundial de Educação em Direitos Humanos (PMEDH 2005/2014) a educação em direitos humanos é entendida como um conjunto de atividades que objetivam a capacitação e a difusão de informação, buscando a criação de uma cultura universal de direitos humanos. Uma educação em direitos humanos não somente proporciona conhecimentos sobre os direitos humanos e os mecanismos para protegê-los, mas que, além disso, proporciona condições necessárias para a promoção e defesa dos mesmos na vida cotidiana.

O PMEDH apresenta metas e ações propostas em cinco eixos: educação básica; educação superior; educação não formal; educação dos profissionais dos sistemas de justiça e segurança; e educação e mídia. Esse plano possui uma ampla

${ }_{14}$ Ver NOVAES, Henrique T.; DIAS, Rafael. Contribuições ao Marco Analítico-Conceitual da Tecnologia Social. In: DAGNINO, Renato (Org.). Tecnologia Social: Ferramenta para construir outra sociedade. Campinas/ SP: IG / UNICAMP, 2009, p. 17-53. 
abrangência e objetiva a formação de uma cultura de respeito à dignidade humana por meio da promoção e da vivência de valores da liberdade, da justiça da igualdade, da solidariedade, da cidadania, da compaixão, etc.

O PMEDH está dividido em duas fases: a primeira fase (2005-2009) visa a implementação da educação em direitos humanos nos níveis de ensino primário e secundário. A segunda fase (2010-2014) possui como foco o ensino superior e programas de formação em direitos humanos para professoras/es e educadoras/es, servidores públicos, forças de segurança, agentes policiais e militares em todos os níveis de formação.

Com o Plano Nacional de Educação em Direitos Humanos (PNEDH) de 2007, foi formalizada a recomendação da inclusão, nos currículos escolares, da discussão sobre a discriminação e a necessidade de um tratamento igualitário a todas as pessoas.

[...] Todas as pessoas, independente do seu sexo; origem nacional, étnico-racial, de suas condições econômicas, sociais ou culturais; de suas escolhas de credo; orientação sexual; identidade de gênero, faixa etária, pessoas com deficiência, altas habilidades/superdotação, transtornos globais e do desenvolvimento, têm a possibilidade de usufruírem de uma educação não discriminatória $e$ democrática (BRASIL, 2007, p. 32).

Essas são as diretrizes a serem colocadas em prática, havendo necessidade de se propor medidas legislativas e políticas que garantam a diminuição das violências e desigualdades, reconhecendo a equidade de gênero. Podemos destacar ainda os eixos temáticos contidos no Plano Nacional de Educação em Direitos Humanos, "[...] raça, nacionalidade, etnia, gênero, classe social, região, cultura, diversidade religiosa, orientação sexual, identidade de gênero, geração $e$ deficiência (BRASIL/PNEDH, 2007). Ficam com a responsabilidade pela efetivação das diretrizes os sistemas de ensino e suas instituições, devendo ser adotadas por todas as pessoas envolvidas nos processos educacionais. 
Neste contexto, a educação em direitos humanos é entendida como uma possibilidade de combate a todas as formas de intolerância, desrespeito, discriminação contra as pessoas e de violação aos direitos humanos. Além disso, a educação em direitos humanos deve promover atitudes e comportamentos necessários para que os direitos humanos de todos/as os/as integrantes da sociedade sejam respeitados.

A discussão da temática de direitos humanos no campo da educação é imprescindível na perspectiva da construção de uma cultura de direitos humanos para todas/os (homens, mulheres, negros, negras, pobres, ricos, povo da cidade, povo do interior, moradores de rua, crianças, jovens e adultos), especialmente por meio de espaços democráticos de debate dentro e fora da escola, que privilegiem uma sociedade inclusiva e humanizadora. Segundo Severino "a educação só é humanizadora se for intencionalizada pelo conhecimento e pela valoração, desde que referidos à significação apreendida na existência histórico-social" (2001, p. 9).

\section{Considerações}

Retornando ao foco da análise, constatamos que a Declaração dos Direitos Humanos desde uma Perspectiva de Gênero (DUDHG) reflete o amadurecimento das feministas contemporâneas e seus diferentes movimentos, lutas reivindicatórias e por emancipação de sujeitos. Ao ser dirigido a ONU por ocasião do cinquentenário da Declaração Universal dos Direitos Humanos, de um lado, questiona e relativiza o conceito do ser humano contido aí, em grande medida, como dizem, "limitado ao do macho, ocidental, branco, adulto, heterossexual $e$ dono de um patrimônio". Portanto, denuncia a ausência da perspectiva de gênero na Declaração dos Direitos Humanos que orienta e apontam direitos há meio século. Por outro lado, as mulheres já não se satisfazem com declarações, legislações ou código locais, regionalizados ou nacionais. E aí, observamos outro avanço: num mundo globalizado, propõem-se uma Declaração de Direitos na perspectiva de Gênero, também global, sem invalidar as conquistas da Declaração Universal. Além disso, os direitos humanos garantidos nem sempre se efetivam na 
prática ou alcançam abrangência universal, considerando-se classe social, relações étnico-raciais, geração, religião, deficiência, localização (rural/urbano), entre outros fatores, existe ainda grupos de mulheres em situação de desvantagem social.

Scott (1999, p. 203), questiona o alcance das teorias feministas desenvolvidas até a década de 1980, afirmando que o feminismo necessita de teorias que permitam pensar gênero em termos de pluralidade de diversidades, em lugar de unidade e universais; que rompam o esquema conceitual dessas velhas tradições filosóficas ocidentais que tem construído e repetido sistematicamente o mundo de maneira hierárquica, em termos de universos masculinos $e$ especificidades femininas; que permitam articular modos de pensamento alternativos sobre gênero (portanto maneiras de atuar) que vão além de reverter as velhas hierarquias ou confirmá-las; que seja útil e relevante para a prática política.

A DUDHG, em grande medida, revela uma compreensão teórica de gênero, que segundo nosso entendimento, responde às expectativas de Scott. Por quê? Primeiro reivindica o direito à igualdade no tratamento dos direitos para homens e mulheres, reafirmando a indivisibilidade, a universalidade $e$ interdependência dos direitos humanos; segundo, evoca as diferenças, nas relações de gênero, quando coloca a mulher protagonista dos direitos de definir questões sobre direitos sexuais e reprodutivos.

Entretanto, da discussão política à prática, sempre há um longo caminho a percorrer. Até o presente momento histórico, constatamos alguns esforços da ONU em incorporar a "Declaração dos Direitos Humanos desde uma Perspectiva de Gênero" na Declaração Universal dos Direitos. Proclamou "o ano internacional da mulher" ${ }^{15}$, criou a ONU MULHER ${ }^{16}$ ou ONU para a Igualdade de Gênero e o

${ }^{15}$ A Assembleia Geral declarou o ano de 1975 como o Ano Internacional das Mulheres e organizou a primeira Conferência Mundial sobre as Mulheres, na Cidade do México. Também, os anos de 1976 a 1985 foram declarados como sendo a Década da Mulher.

${ }^{16}$ A Assembleia Geral da ONU instituiu no dia 02 de julho de 2010 a ONU Mulher que é um órgão para fortalecer a autonomia das mulheres e atingir a igualdade de gênero. Esse novo órgão reúne quatro agências e escritórios da Organização: O Fundo de Desenvolvimento das Nações Unidas para a Mulher (UNIFEM), a Divisão para o Avanço das Mulheres (DAW), o Escritório de Assessoria Especial em Questões de Gênero e o Instituto Internacional de Treinamento e Pesquisa para a 
Empoderamento das Mulheres. A ONU denuncia constantemente violações de direitos e diferentes formas de discriminação, cujas vítimas são as mulheres pelo mundo inteiro, mas ousar numa Declaração dos Direitos considerando o tratamento de gênero no binômio igualdade e diferença numa compreensão complementar e não de oposição ou exclusão, é um desafio a ser enfrentado.

Ainda que as intenções maiores do Comitê não tenham sido asseguradas enquanto declaração, importante é a ação política, o grau de consciência e o processo pedagógico instaurado no interior dos movimentos feministas e do conjunto da sociedade, quem sabe, diria uma/um militante do estilo de Scott, uma vez que nesta perspectiva gênero disputa um campo de relações de poder muito além da microfísica.

\section{REFERÊNCIAS}

ALENCAR, Chico. Para Humanizar o Bicho Humano. In: ALENCAR, Chico. (org.). Direitos Humanos. Rio de Janeiro: Garamond, 1998.

BOBBIO, Norberto. A era dos direitos. Rio de Janeiro: Campus, 1992.

BRASIL. Plano de Ação. Programa Mundial de Educação em Direitos Humanos. Segunda Fase. Brasília, 2012.

BRASIL. Educação em Direitos Humanos: diretrizes nacionais. Secretaria de Direitos Humanos da Presidência da República. Brasília: Coordenação Geral de Educação em SDH/PR, Direitos Humanos, Secretaria Nacional de Promoção e Defesa dos Direitos Humanos, 2013. (Caderno de Educação em Direitos Humanos)

BRASIL. Secretaria de Direitos Humanos da Presidência da República. Programa Nacional de Direitos Humanos (PNDH-3). Secretaria Especial dos Direitos

Promoção da Mulher (INSTRAW). Informações disponíveis em: http://www.onu.org.br/a-onu-emacao/a-onu-e-as-mulheres/; Acesso: 16 de janeiro de 2015. 
Humanos da Presidência da República. Ver. e atual. Brasília: SEDH/PR, 2010. 308p.

BRASIL. Plano Nacional de Educação em Direitos Humanos. Comitê Nacional de Educação em Direitos Humanos. Brasília: Secretaria Especial dos Direitos Humanos, Ministério da Educação, Ministério da Justiça, UNESCO, 2007.

BRASIL. Ministério da Educação. Conselho Nacional de Educação. Conselho Pleno. Resolução No 1, de 30 de maio de 2012. Estabelece Diretrizes Nacionais para a Educação em Direitos Humanos, 2012. Disponível online em: http://portal.mec.gov.br/index.php?option =com docman\&view=download\&alias $=10889$-rcp001-12\&category slug=maio-2012-pdf\&Itemid=30192; Acesso: 11 de abril de 2016.

CLADEM - Comitê Latino Americano e do Caribe para a Defesa dos Direitos da Mulher. Declaração dos Direitos Humanos de uma Perspectiva de Gênero. Contribuição ao $50^{\circ}$. Aniversário da Declaração Universal dos Direitos Humanos. Documento no. E/C. 4/1998NGO/3. Comissão de Direitos Humanos das Nações Unidades - Genebra. (mimeo - s/d).

CARTA DA TERRA. Disponível em: http://www.cartadaterrabrasil.org/prt/text.html; Acesso: 16 de janeiro de 2015.

DECLARAÇÃO DE DIREITOS DO HOMEM E DO CIDADÃO 1789. Universidade de São Paulo. Biblioteca Virtual de Direitos Humanos (1978). Disponível em: http://www.direitoshumanos.usp.br/index.php/Documentosanteriores-\%C3\%A0-cria\%C3\%A7\%C3\%A3o-da-Sociedade-das-

Na\%C3\%A7\%C3\%B5es-at\%C3\%A9-1919/declaracao-de-direitos-do-homem-edo-cidadao-1789.html; Acesso: 14 de janeiro de 2015.

DECLARAÇÃO DE DIREITOS DA MULHER E DA CIDADÃ - 1791. Universidade de São Paulo. Biblioteca Virtual de Direitos Humanos. Disponível em: http://www.direitoshumanos.usp.br/index.php/Documentos-anteriores-\%C3\%A0cria\%C3\%A7\%C3\%A3o-da-Sociedade-das-Na\%C3\%A7\%C3\%B5es-at\%C3\%A91919/declaracao-dos-direitos-da-mulher-e-da-cidada-1791.html; Acesso: 14 de janeiro de 2015.

HOBSBAWM, Eric. Era dos Extremos. São Paulo: Companhia das Letras, 1998.

MARX, Karl. "A questão judaica". In: Manuscritos Económicos-filosóficos. Lisboa: Edições 70, 1993.

MANCE, Euclides André. Fome Zero e Economia Solidária: O desenvolvimento sustentável e a transformação Estrutural do Brasil. Curitiba: Editora Gráfica Popular. 2004. 
NOVAES, Henrique T.; DIAS, Rafael. Contribuições ao Marco Analítico-Conceitual da Tecnologia Social. In: DAGNINO, Renato (Org.). Tecnologia Social: Ferramenta para construir outra sociedade. Campinas/ SP: IG / UNICAMP, 2009, p. 17-53.

SILVA, Alain Tramont; NUNES, Pedro Henrique. Olympe de Gouges: as mulheres e a revolução. Disponível em:

http://www.historia.uff.br/nec/olympe-de-gouges-mulheres-e-revolucao; Acesso: 08 de abril de 2016.

ORGANIZAÇÃO DAS NAÇÕES UNIDAS (ONU). Declaração Universal dos Direitos Humanos. Legislação internacional adotada e proclamada pela Resolução n 217 A da $3^{a}$ Sessão Ordinária da Assembleia Geral das Nações Unidas, em 10 de dezembro de 1948. Disponível em: http://portal.mj.gov.br/sedh/ct/legis intern/ddh bib inter_universal.htm; Acesso: 14 de janeiro de 2015.

ORGANIZAÇÃO DAS NAÇÕES UNIDAS (ONU). ONU Mulheres. Disponível em: http://www.onu.org.br/a-onu-em-acao/a-onu-e-as-mulheres;

http://www.unwomen.org/; Acesso:16 de janeiro de 2015.

PEDRO, Joana Maria. Relações de gênero como categoria transversal na historiografia contemporânea. Topoi, v. 12, n. 22, jan.-jun. 2011, p. 270-283. Disponível online: http://www.scielo.br/pdf/topoi/v12n22/1518-3319-topoi-12-2200270.pdf; Acesso: 11 de abril de 2016.

PITANGUY, Jacqueline; MIRANDA, Dayse. As mulheres e os direitos humanos. In: O Progresso das Mulheres no Brasil. UNIFEM, Fundação Ford, CEPIA. Brasília, 2006.

SCOTT, Joan W. Igualdade versus diferença: os usos da teoria pós-estruturalista. Debate Feminista. Cidadania e feminismo, 1999, p. 203 a 223.

- Gênero: Uma Categoria Útil de Análise Histórica. Educação e Realidade. Vol.2, nº 02, jul./dez., 1995. SEVERINO, Antônio Joaquim. Educação, sujeito e história. São Paulo: Olho D’Água, 2001.

UNESCO. World Programme for Human Rights Education: second phase; plan of action, 2012. (ACNUDH).

UNESCO. Plano de ação - Programa Mundial para Educação em Direitos Humanos. Brasília: Organização das Nações Unidas para a Educação, a Ciência e a Cultura, 2012.

ZENAIDE. Maria de Nazaré Tavares. Educação em e para os Direitos Humanos: Conquista e direitos. In: ZENAIDE. Maria de Nazaré Tavares (org.). Direitos Humanos: capacitação de educadores. João Pessoa: Editora Universitária/ UFPB, 2008, v. 2. p. 127-142. Disponível online em: 
http://www.dhnet.org.br/dados/livros/edh/a pdf/livro dirhumanos volume2.pdf; Acesso: 08 de abril de 2016.

ZENAIDE. Maria de Nazaré Tavares (org.). Direitos Humanos: capacitação de educadores. João Pessoa: Editora Universitária/ UFPB, 2008, v. 1. p. 147

Disponível online em:

http://www.dhnet.org.br/dados/livros/edh/a_pdf/livro_dirhumanos_volume2.pdf; Acesso: 08 de abril de 2016.

ZENAIDE. Maria de Nazaré Tavares (org.). Direitos Humanos: capacitação de educadores. João Pessoa: Editora Universitária/ UFPB, 2008, v. 2. p. 218. Disponível online em: http://www.dhnet.org.br/dados/livros/edh/a_pdf/livro dirhumanos_volume2.pdf; Acesso: 08 de abril de 2016. 